\title{
ENGINEERING GEOLOGICAL BEHAVIOUR OF HETEROGENEOUS AND CHAOTIC ROCK MASSES
}

\author{
Tsiambaos G. \\ National Technical University of Athens, School of Civil Engineering, Department of \\ Geotechnical Engineering,gktsiamb@central.ntua.gr
}

\begin{abstract}
The engineering characterization of heterogeneous and complex geological formations for estimating their rock mass strength and deformability characteristics constitutes a challenge to geo-scientists and engineers dealing with the design and construction of slopes and tunnels. Mélanges and similar heterogeneous mixtures of hard blocks in weaker matrix, known as "bimrocks", present an overall strength significantly greater than the matrix strength, because the presence of rock blocks, above a threshold volumetric proportion, influences the mechanical characteristics and the behaviour of these rock masses. Moreover, recent studies have shown that the strength and mechanical behaviour of heterogeneous and composite rock masses such as flysch and molasses consisting of alternating layers of competent and incompetent rocks are governed by the presence and volumetric percentage of the interlayers of the weaker rocks.
\end{abstract}

Key words: heterogeneous rock masses, composite rocks, mélanges, rock strength, laboratory testing.

\section{Introduction}

The quantitative description, characterization and classification of heterogeneous and chaotic rock masses, as well as the estimation of their strength and deformability are of great importance for the design of surface and underground engineering woks.

Complex geological mixtures such as melanges, fault rocks, tectonic breccias, pyroclastic rocks and sheared ophiolites can be considered as mixtures of blocks of competent rock embedded within a weaker matrix (block-in-matrix rocks or bimrocks, as introduced by Medley, 1994). The overall uniaxial compressive strength and the shear strength characteristics of these rocks depend on the rock block proportions, taking into account the scale of engineering interest (laboratory to site scale).

Furthermore, heterogeneous and composite rock masses such as flysch and molasses consisting of alternating layers of two or more lithological units (mainly sandstone, siltstone or shale) present a strongly anisotropic behaviour. The first attempt to characterize, from an engineering geological point of view, and to present a methodology for estimating the Geological Strength Index (GSI) of these rock masses was made by Marinos and Hoek (2001) and Hoek et al. (2005).

Recent laboratory studies have indicated that the overall strength and deformability characteristics of layered composite rocks are mainly governed by the relative thickness of competent and incompetent constituents and especially the volumetric percentage of the weaker member. 


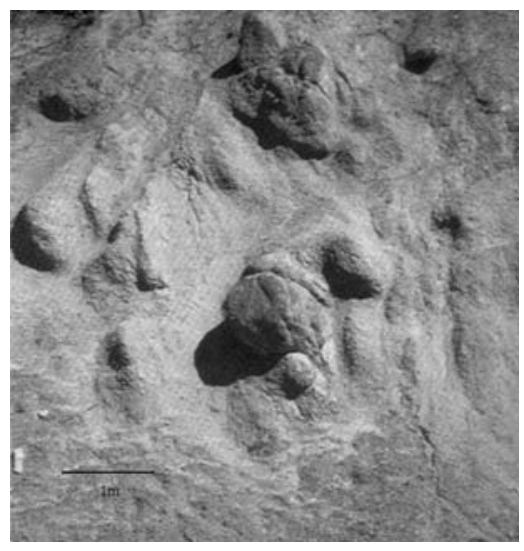

Fig. 1: Blocks of moderately weathered granite in a completely weathered mass.

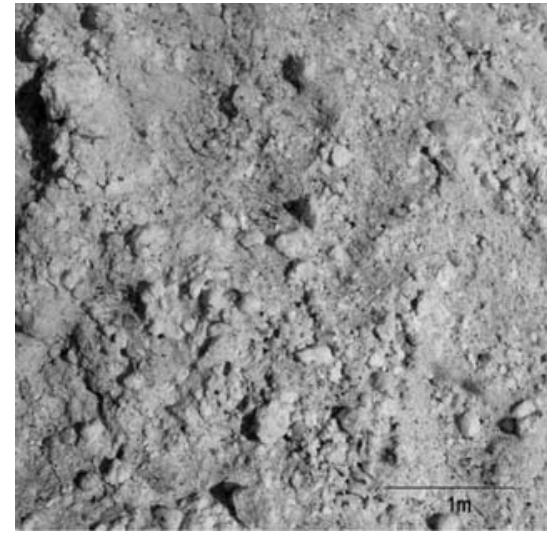

Fig. 2: Fault breccia.

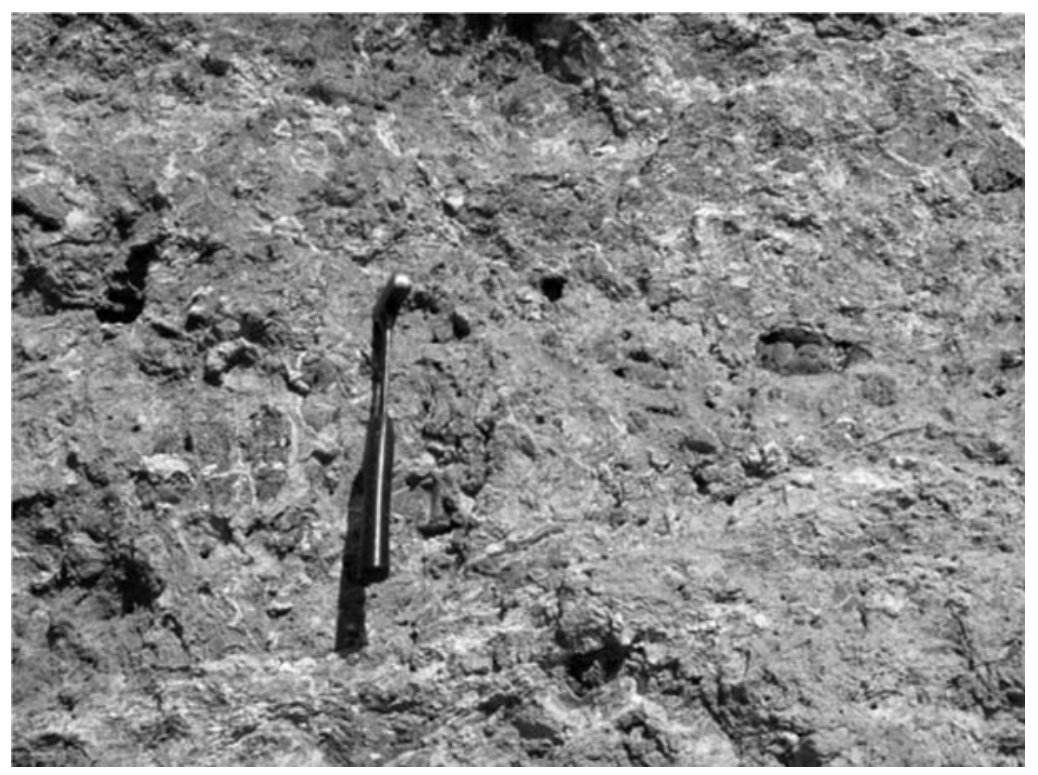

Fig. 3: Ophiolitic mélange (blocks of serpentinized peridotites in a volcano-sedimentary matrix).

\section{Block-in-matrix rocks (Bimrocks)}

\subsection{Origin}

The term "block-in-matrix rocks" was originally introduced by Raymond (1984) as "blocks of one lithology enclosed in materials of another lithology". This term is applied for heterogeneous, complex geological formations, tectonically deformed and disturbed, containing competent blocks of varied lithologies embedded in weaker bonded matrix rocks of finer texture, such as mélanges, sheared serpentinites, olistostromes, cataclastic fault rocks, weathered rocks and coarse pyroclastics (Figures 1,2 and 3). The blocks range between several tens to hundreds of meters in size to millimeter-sized fragments within gouge. Medley (1994), suggested the neutral word "bimrocks" in order to characterize these "rock/ soil" mix- 
tures and study their peculiar behaviour from an engineering point of view. The same author defined "bimrocks" as "a mixture of rocks composed of geotechnically significant blocks within a bonded matrix of finer texture". The expression "geotechnically significant blocks" means that there is a strength contrast between blocks and matrix, and consequently the volume and size of the blocks greatly influence the rock mass strength and deformability at the scales of engineering interest. Medley (1994) has suggested a threshold value of at least two (2) for the ratio of the uniaxial compressive strength (UCS) of rock blocks to UCS of matrix for a geological rock mixture to be considered as a bimrock.

\subsection{Scale effects}

The engineering behaviour of these rocks is controlled by the presence both of bocks and matrix. It must be noted that neglecting the presence of rock blocks and considering only the strength of the weak matrix, is too conservative in estimating the overall strength of bimrocks. As rock block proportion increases, strength and stiffness increase and deformability decreases depending on the relative orientation of blocks to applied stresses (Lindquist, 1994; Lindquist and Goodman, 1994). The weakest elements in bimrocks are the contacts between strong blocks and weak matrix, since matrix shear zones generally pass around blocks via the block/matrix contacts with the most intense shearing often present adjacent to the largest blocks.

Stress distributions in bimrocks depend on the lithologies; size distributions; orientations and shapes of blocks; and the orientations of matrix shears. All these factors influence stability of slopes (Medley and Sanz, 2004) and underground excavations (Button et al., 2003; Moritz et al., 2004; Riedmüller and Schubert, 2002).

Block sizes in mélanges can exceed several orders of magnitude, ranging between millimeters and tens of kilometers (Medley, 1994; Medley and Lindquist, 1995) and consequently small blocks at one scale of interest (i.e. laboratory rock specimen) may be part of the matrix at a larger scale (tunnel diameter). In order to study the scale effects in bimrocks, Medley (1994) introduced a "characteristic engineering dimension, Lc" which depends on the volume of blocks relative to the dimensions of an engineering project. According to Medley (1994), Lc may variously be: 1) an indicator of the size of the entire site (i,e, landslide area, $A)$, such as the square root of $A(\sqrt{ } \mathrm{A})$ or the landslide depth; 2$)$ the size of the largest block (dmax) at the site; 3 ) the height of a slope or excavation; 4) the tunnel diameter; 5) a footing width or; 6) the dimension of a laboratory specimen.

The smallest geotechnically significant block, as defined above, within a volume of bimrock is about $0.05 \mathrm{Lc}$, which is the threshold size between blocks and matrix at the chosen scale (Medley, 1994). For any given volume of bimrock, blocks smaller than 0.05 Lc constitute greater than 95 percent of the total number but contribute less than 1 percent to the total volume of bimrock. These blocks smaller than the block/matrix threshold dimension have negligible effect on the bimrock strength and are considered as matrix material. The largest geotechnically significant block is about $0.75 \mathrm{Lc}$. In the case of the foundation of a bridge pier of $2 \mathrm{~m}$ diameter $(\mathrm{Lc}=200 \mathrm{~cm})$, blocks with dimensions smaller than $10 \mathrm{~cm}$ $(0.05 \mathrm{Lc})$ are consider as matrix. For the same bimrock, where a $20 \mathrm{~m}$ diameter tunnel excavation is considered, rock blocks with dimensions up to $100 \mathrm{~cm}$ belong to the matrix of the whole rock mass.

\subsection{Estimation of volumetric block proportions}

As indicated above, to predict the mechanical properties of bimrocks, the volumetric block proportion must be estimated in the engineering project site. When adequate number of boreholes has been executed in the site, the volumetric block proportion (VBP) of a bimrock can be approximated by measuring lin- 


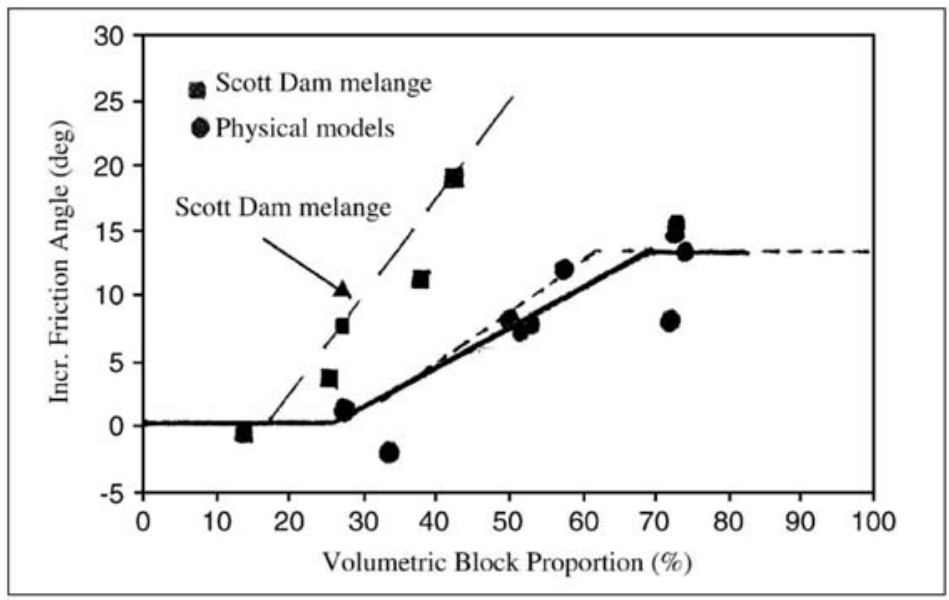

Fig. 4: Strength dependence of bimrocks on volumetric block proportion (after Medley, 1999).

ear block proportions of drilled cores (Medley, 1994). The linear block proportion can be estimated as the ratio of the total length of rock cores to the total length of drilling. The minimum required length of sampling boreholes in total must be at least 10 times the size of the expected largest block in the bimrock (10Lc, or 10dmax). Using the measurement of drilled cores or scanlines on photographs for the VBP estimation are considered as one-dimensional (1-D) methods. Moreover, geological mapping and image analysis on scanned images or photographs from outcrops in the site of the engineering project are examples of two-dimensional (2-D) methods. Sieve analysis of bimrock samples is a three-dimensional (3-D), but can be used only for laboratory investigations of weak rocks, when separation of blocks from matrix is possible. If a significant density contrast between blocks and matrix exists, the overall density of the laboratory cylindrical specimens will vary directly in proportion to VBP.

\subsection{Bimrock strength}

Irfan and Tang (1993), Lindquist (1994) and Lindquist and Goodman (1994) determined that the overall strength of a bimrock is related to the volumetric proportion of the blocks. Lindquist (1994) suggested that below about 25 percent volumetric block proportion, the strength and deformation properties of a bimrock is that of the matrix; between about 25 percent and 75 percent, the friction angle and modulus of deformation of the bimrock mass proportionally increase (Figure 4). Beyond 75 percent block proportion, the blocks tend to touch each other and there is no further increase in bimrock strength, since the strength of the individual blocks is generally considered to has no effect on the bimrock overall strength (Medley, 1994).

In order to investigate the shear strength characteristics of bimrocks, laboratory specimens could be considered as scale models of the in situ rock masses. Given that the diameter of the laboratory specimens is the characteristic engineering dimension (Lc), blocks included in the specimens are considered to be those with maximum dimensions between about 0.05 ( 5 percent) and 0.75 ( 75 percent) of the specimen diameter (in case of cylindrical specimens). The volumetric block proportions of each specimen can be determined after disaggregating them and wash sieving to retrieve the blocks. The volume of blocks (and thence the volumetric block proportion) can also be estimated by measuring the specific gravity of the blocks and weighing the specimens (Lindquist, 1994a). Medley (1994) described methods of approximating block proportions from scanlines drawn on the side of specimens or image analysis of specimen exteriors, although these measures are generally not the same as volumetric proportions. 


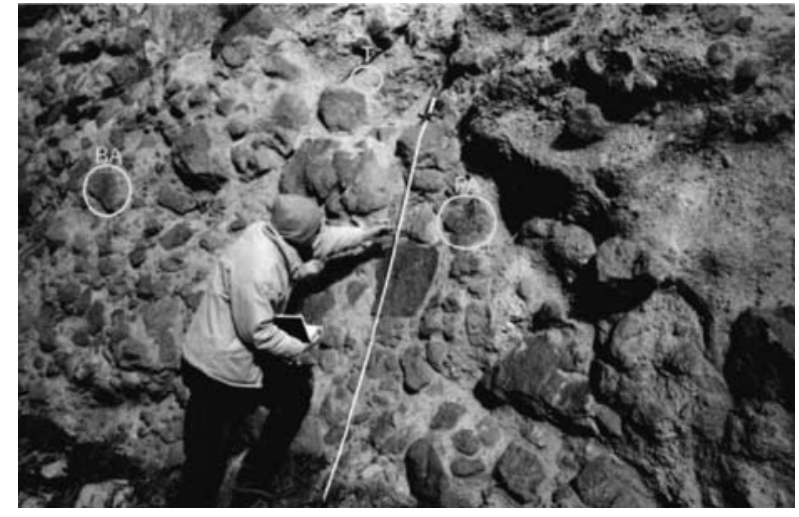

Fig. 5: Outcrop of volcanic block and tuff mixture (after Sönmez et al., 2004). PA: pink andesite blocks, BA: black andesite blocks; T: tuff.

Laboratory specimens of bimrocks exhibiting a range of volumetric block proportions could be tested using multistage triaxial compression or direct shear tests for measuring effective friction angle and cohesion as a function of volumetric block proportion. The overall volumetric block proportion of the bimrock, as estimated from borehole data, can be used to determine the strength of the bimrock on site.

Sönmez et al. $(2004,2006)$ studied the mechanical behaviour of Ankara agglomerate, a mixture of volcanoclastic blocks and tuff matrix. The blocks ranged in size from a few centimetres to about one meter (Figure 5). The 2D measurements of blocks in the Ankara Agglomerate revealed that these blocks composed of pink (lighter) and black (darker) andesite ranged between 1 and $70 \mathrm{~cm}$ (mean value, $11 \mathrm{~cm}$ ).

By conducting uniaxial compression tests on specimens of andesite rocks, it was determined that the average values of UCS for pink and black andesite blocks are about 50 and 90 MPa respectively and that of the tuff matrix $10 \mathrm{MPa}$. The minimum and maximum ratio of UCS of blocks to the UCS of tuff matrix is 2.5 and 19, respectively. The maximum and minimum UCS values of NX-size core specimens of Ankara Agglomerate were 5.7 and 55 MPa, respectively, and the average UCS value was 24.9 MPa.

However, separation of the andesite blocks from weak tuff matrix was impossible by using sieve analysis because of the tuff matrix acting as cementing agent. So, image analysis methods were used to estimate the volumetric block proportions. However, a composite block proportion was used to study the differences in overall UCS due to differences in the proportions of the two different andesite block types. A weighted "equivalent block proportion", or EBP, accommodates two or more types of blocks differing in individual mechanical properties:

$$
\mathrm{EBP}=\sum_{\mathrm{i}}^{\mathrm{n}} \mathrm{VP}_{\mathrm{i}} \frac{\mathrm{UCS}_{\mathrm{i}}}{\mathrm{UCS}_{\text {max_block }}}
$$

where, $\mathrm{VP}_{\mathrm{i}}$ is the volumetric block proportion of ith block, UCS is the uniaxial compressive strength, $\mathrm{n}$ is the number of different types of blocks, and $\mathrm{UCS}_{\text {max _block }}$ is the uniaxial compressive strength of the stronger block type.

The uniaxial compressive strengths of the Ankara Agglomerate specimens were then normalized by dividing them by the average uniaxial compressive strength of the matrix: this parameter is denoted as $\mathrm{UCS}_{\mathrm{N}}$. The relationships of Figure 6 are non-linear, particulary above about $70 \%$ equivalent block proportion, suggesting that the dependence of overall bimrock strength on block proportion is more complex than previously understood and further study is required. The plot also indicates that at high equivalent block porportions the overall bimrock becomes uniformally stronger. 


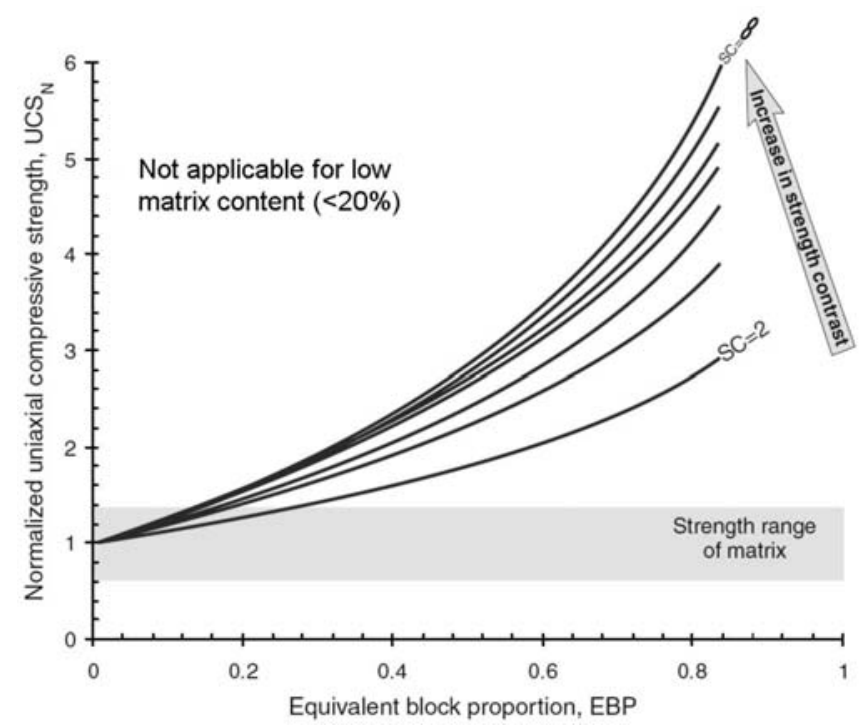

Fig. 6: Relationships between equivalent block portion (EBP) and UCS of Ankara agglomerate, with lines of different strength contrast (ratios) between andesite blocks and tuff matrix (after Sonmez et al., 2006).

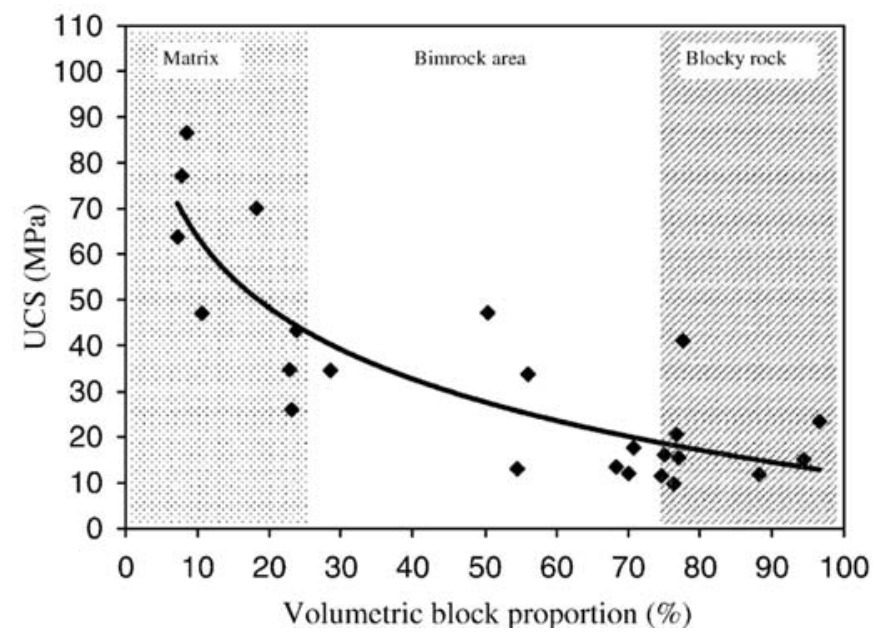

Fig. 7: Volumetric Block Proportion (VBP) versus Uniaxial Compressive Strength (UCS) for a fault cemented tectonic breccia (after Kahraman and Alber, 2006).

This behaviour shows that at high volumetric block proportions (greater than about 70 to $75 \%$ ), block/matrix rock mixtures should be considered as very blocky to disintegrated rock masses, according to GSI (Marinos and Hoek, 2000) for which the Hoek-Brown failure criterion (Hoek et al., 2002) should be successfully applied.

Kahraman and Alber (2006) studied the unconfined compressive strength of a fault cemented tectonic breccia consisting of weak, weathered slate components (blocks of various dimensions) and strong matrix consisting of recrystalized limestone. According to the testing results, the UCS of the breccia specimens decreases as the volumetric block proportion, VBP, increases, as shown in Fig- 
ure 7. These results are different from the findings of Sönmez et al. (2004, 2006). The difference between the two studies is due to the matrix type. The matrix of Ankara Agglomerate was weaker than the andesite blocks, whereas the matrix of fault breccia studied by Kahraman and Alber (2006) was stronger than the weak blocks of slate.

Karzulovic and Diaz (1994) studied the behaviour of a cemented breccia (Braden Breccia, Chile) for the design of underground openings in this rock. Any attempt to classify the rock mass was unsuccessful due to the presence of only few discontinuities. Therefore, it was decided to treat this rock mass as a weak but homogeneous "almost intact" rock and to determine its properties by means of triaxial tests on 100mm diameter specimens (Hoek, 2007). The in situ GSI value of this breccia was estimated (not measured) close to 75 by a back analysis of the behaviour of underground openings and taking into account the laboratory results of the specimens tested.

Marinos et al. (2005) presented a quantitative description of ophiolitic complex rock masses, using the GSI, and described the effects of serpentinisation and shearing on the mechanical behaviour of these rock masses in underground excavations. They considered low to very low GSI values (10 to 20) for ophiolite melanges and since it is very difficult to obtain $\sigma_{\mathrm{ci}}$ from laboratory tests, they derived values of $\sigma_{\mathrm{ci}}$ and $\mathrm{m}_{\mathrm{i}}$ from a back analysis of the behaviour of tunnels excavated in these rock masses. However, when these rocks have a soil-like behaviour the GSI assignment is meaningless.

Carter et al. (2007) stated that, although the Hoek-Brown non-linear criterion (Hoek et al., 2002) for strength estimation of rock masses based on GSI classification system (Marinos and Hoek, 2000) proven in general remarkably successful for defining rock mass behaviour for underground and surface rock excavations, however difficulties have been experienced for very low strength rocks, i.e exhibiting an unconfined compressive strength, $\mathrm{UCS}=\sigma_{\mathrm{ci}}$ lower than about $15 \mathrm{MPa}$, because in such cases the rock mass behaviour is less controlled by discontinuities. For these weak rocks Carter et al. (2007) proposed a transition (function of UCS $=\sigma_{\text {ci }}$ ) for rock masses and Mohr-Coulomb equivalent strength predictions for soils.

In many cases, mélanges or sheared serpentinites and other weak rocks with similar structure could be considered as bimrocks and their strength and deformation characteristics could be estimated by using the approach mentioned above for these rocks.

It must be noted that all the previous works for bimrocks have not considered their strength anisotropy due to blocks shape and orientation, which is an important factor since foliated and sheared bimrocks could exhibit a high anisotropic behavior.

\subsection{Shear strength of tectonically disturbed and weathered flysch}

Flysch represents a typical structurally complex formation with a wide distribution in central and western Greece. Heterogeneity of lithology, intense folding, shearing with numerous overthrusts and weathering, are the main reasons of critical slope stability and the activation of large scale landslides in this formation. The study of large landslides in tectonically disturbed and weathered flysch, affecting the road Trikala to Arta, close to the Elati village, showed that the sliding mass had a thickness of about 10m (Christoulas et al., 1988). The characteristic engineering dimension (Lc) for the landslide can be assumed equal to the average thickness of the slide $(10 \mathrm{~m})$. The block/matrix threshold was thus selected as $0.5 \mathrm{~m}(0.05 \mathrm{Lc})$, whereas the maximum dimension of observed blocks of sandstone or overthrusted limestone in the weathered zone of flysch was $3-5 \mathrm{~m}$. The exploration of the landslide area indicated that proportion of rock blocks with dimensions greater than the threshold value of $0.5 \mathrm{~m}$ is about 20 $30 \%$ (volumetric block proportion of weathered zone of flysch). 


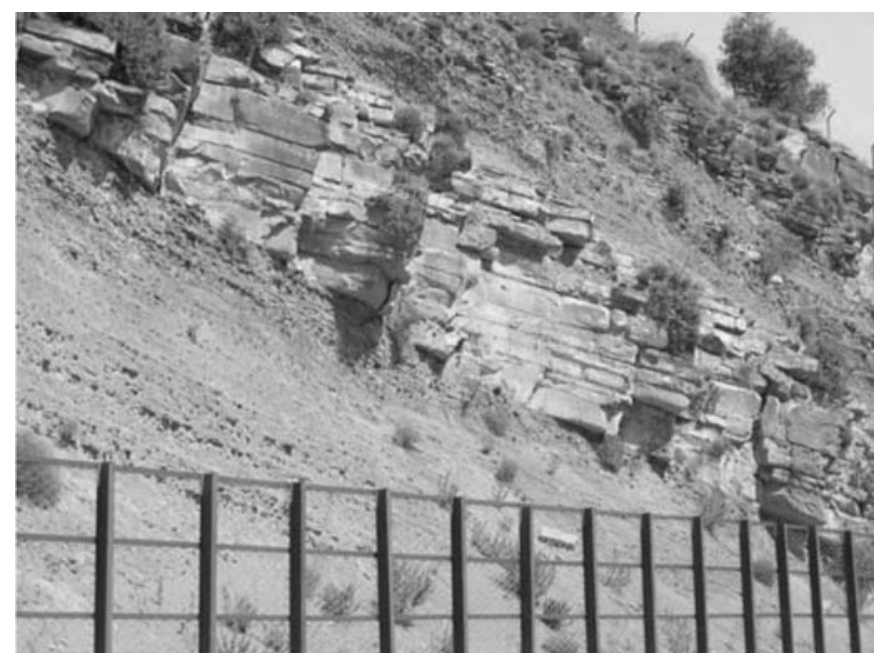

Fig. 8: Alternated layers of sandstones and siltstones of flysch formation (Evinochori region).

The shear strength characteristics of weathered flysch was determined by testing specimens in the large shear box apparatus, 300mm square and about 160mm thick (Christoulas et al., 1988, Kalteziotis and Tsiambaos, 1994). The weathered flysch specimens were prepared with different block proportions ("gravels" percentage with dimensions greater than about $8 \mathrm{~mm}$, i.e. greater than $5 \%$ of the shear box thickness). The determined effective angle of friction was as high as $35^{\circ}-40^{\circ}$ for the specimens exhibiting a volumetric block proportion of about $20 \%$, as estimated by sieve analysis. Moreover, the fine grained portion of the flysch was tested in ring shear apparatus in order to estimate the residual shear strength characteristics of fine grained material of weathered flysch. The measured angle of friction of this material, representing the matrix of the weathered flysch, was ranged from $19^{0}$ to $21^{0}$. It is obvious that considering the low values of angle of friction for slope stability analysis can lead to very conservative results. On the contrary, the specimens tested in the laboratory with volumetric block proportions almost the same as those of the in situ weathered flysch gave more representative shear strength characteristics (angle of friction $35^{\circ}-40^{\circ}$ ). These estimated values of friction angle (considering no cohesion of disturbed flysch) can better explain the slope instability after taking into account the role of ground water and the pore pressure developed during the rainy season.

\section{Heterogeneous, composite rock masses}

Heterogeneous and composite rock masses are those consisting of two or more lithological units exhibiting a structure of alternating layers of competent and incompetent rocks with varying thickness.

Flysch and molasse constitute characteristic examples of such rocks. They are characterized by rhythmic alternations of sandstone and pelitic (fine grained) rocks such as siltstones, marls, shales and clay shales (Figure 8). Conglomerates and limestones can also be present.

For the benefit of the design of a large number of engineering projects in Greece in these rock masses, Marinos and Hoek (2001), Hoek et al. (2005) and Marinos (2010) suggested modified charts for estimating the GSI for these heterogeneous and composite rock masses, based on the lithology, structure and surface conditions (for bedding planes in particular). They excluded from this procedure rock masses with predominant weak planar discontinuities which are probable to cause structurally controlled failures. 


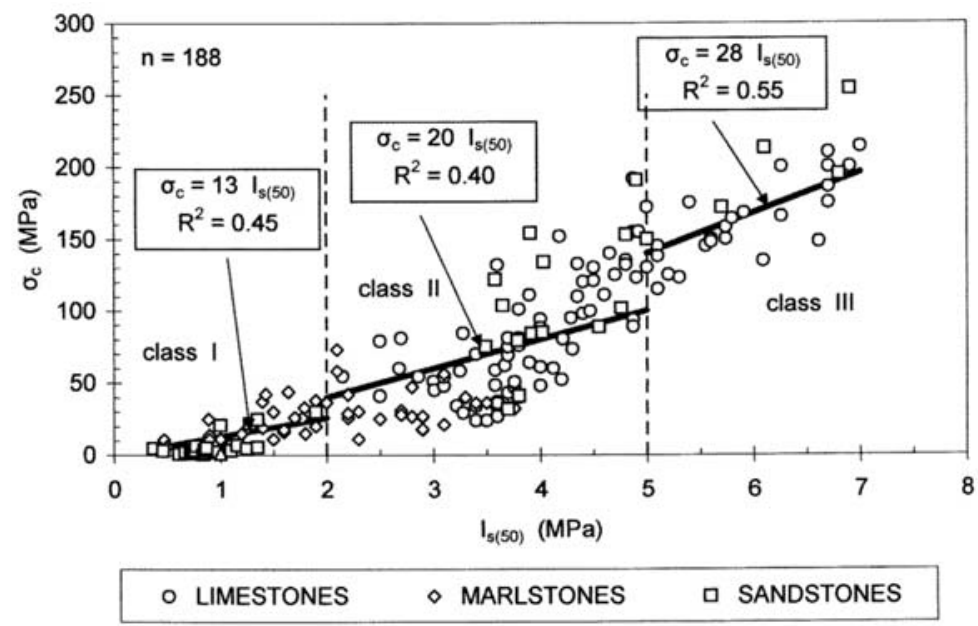

Fig. 9: Conversion factors correlating point loading and uniaxial compressive strength for soft to strong sedimentary rocks (after Tsiambaos \& Sabatakakis, 2004).

Regarding the selection of the "intact" rock properties $\sigma_{\mathrm{ci}}$ and $\mathrm{m}_{\mathrm{i}}$, for flysch composite rocks, they suggested proportions of values ("weighted average") for each rock mass type of the proposed modified charts, reducing values of $\sigma_{\mathrm{ci}}$ and $\mathrm{m}_{\mathrm{i}}$ of competent rocks (sandstones) up to $40 \%$, when the layers of these rocks are separated from each other by weaker layers of siltstones or shales. Therefore, having defined the parameters $\sigma_{\mathrm{ci}}, \mathrm{m}_{\mathrm{i}}$ and GSI, the mechanical properties of the heterogeneous rock mass are estimated by using the Hoek-Brown failure criterion (Hoek and Brown, 1997).

It must be noted that from the weak members of these heterogeneous rock masses it is very difficult to obtain "intact" core samples for determining the uniaxial compressive strength in the laboratory. Moreover, laboratory tests carried out on core samples often result in a lower strength value due to sampling and preparation disturbance. Marinos and Hoek (2001) insist that using the results of such tests in the Hoek-Brown criterion will impose a double penalty on the strength (in addition to that imposed by GSI) and will give unrealistically low values for the rock mass strength.

In such cases, the use of the point load test on samples in which the load can be applied normal to the bedding or any other weakness planes for estimating the uniaxial compressive strength of weak rocks is advisable.

Tsiambaos and Sabatakakis (2004) and Sabatakakis et al. (2008) studied the relationship between the uniaxial compressive strength of intact sedimentary rocks and point load index $\mathrm{Is}_{(50)}$ and estimated that the conversion factor $\mathrm{k}\left(\sigma_{\mathrm{ci}}=\mathrm{k} \mathrm{Is}_{(50)}\right)$ has no a single value, but varies from 13 for soft sedimentary rocks (i.e. shales and siltstones) exhibiting a value of $\mathrm{Is}_{(50)}<2 \mathrm{MPa}$ to 28 for harder rocks with values of $\mathrm{Is}_{(50)}$ greater than $5 \mathrm{MPa}$ (Figure 9).

The overall strength of heterogeneous and composite rock masses is one of the main research subjects the last decade. Goodman (1993) had emphasized that any combination of more than one lithlogical type of rock exhibiting different properties impose a complex geotechnical engineering problem.

Greco et al. (1993) conducted a study for determining the strength and failure mechanism of composite rocks in the context of the stability analysis of the columns and masonry walls of a Cathedral, built with stones of different rock types. Testing cylindrical specimens made up of disks of various 


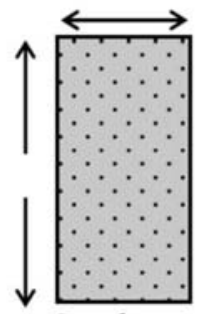

Sandstone

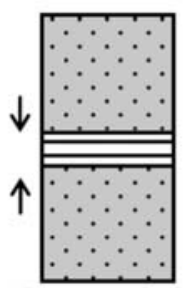

Composite 1

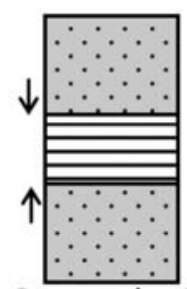

Composite 2

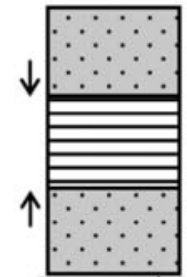

Composite 3

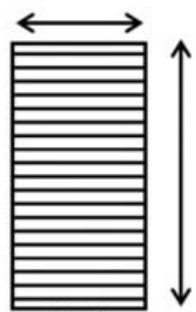

Shale

Fig. 10: Different types of composite specimens consisting of sandstone with shale interlayer (after Zainab et al., 2007).

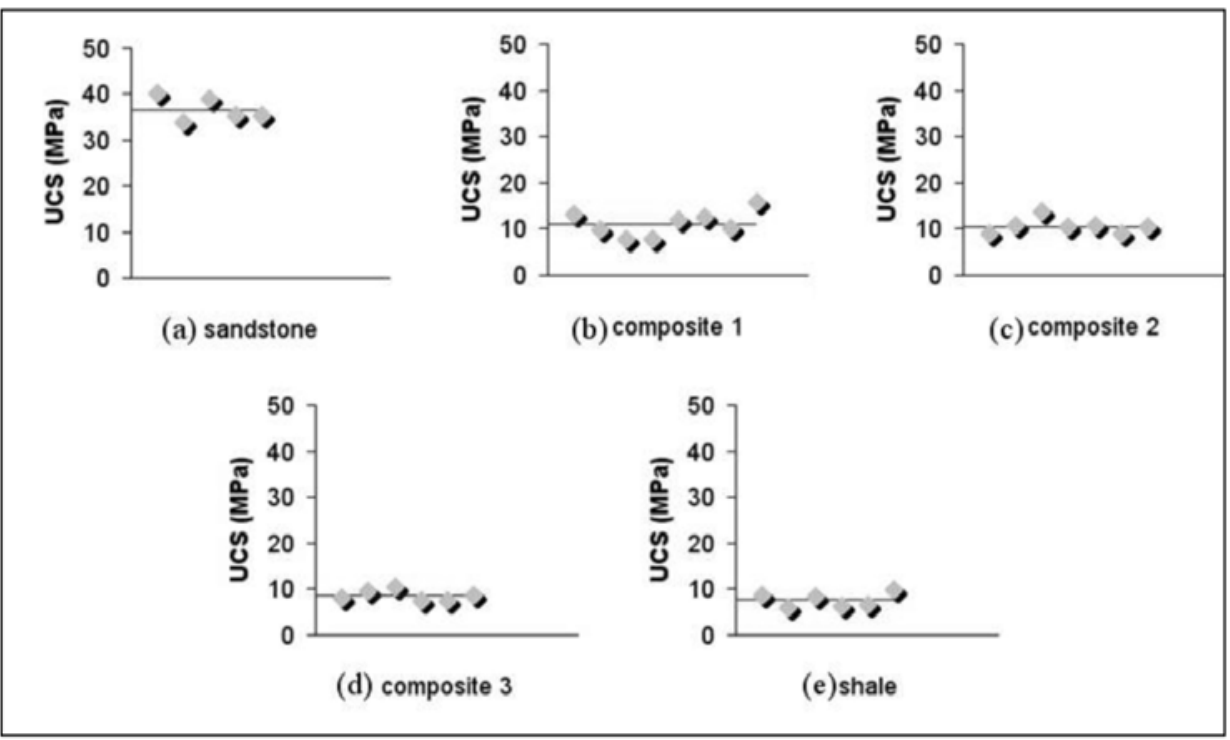

Fig. 11: Uniaxial compressive strength (UCS) of composite specimens illustrated in fig. 10.

rocks, they observed different failure mechanisms for stratified disk specimen from those of single rock, while the loss of compressive strength for composite rock specimens was up to 70 percent in comparison with the uniaxial compressive strength of individual stones.

Zainab et al. (2007) carried out a laboratory study to determine the strength of tropically weathered sandstone and shale in Malaysia. The composite samples were designed into three different thickness ratio of shale to the total height of specimens, $\mathrm{H}$, each having $0.1 \mathrm{H}, 0.2 \mathrm{H}$ and $0.3 \mathrm{H}$ of shale.

Each specimen was then marked as composite 1, composite 2 and composite 3 respectively (Figure 10). These composite samples were prepared to simulate the possible geometry profile of the constituents in the interbedded sedimentary formation.

From the analysis of test results, shown in Figure 11, it is concluded that only a low percentage (i.e. $10 \%$ ) of shale reduces the strength of composite rock specimen drastically by almost $70 \%$. 


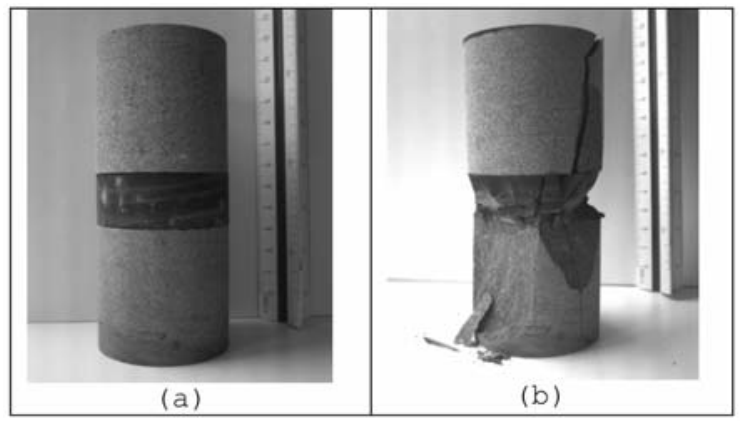

Fig. 12: Cylindrical composite rock specimen made up of sandstone (light grey) with siltstone interlayer (dark grey): (a) pre-failure, (b) post-failure.

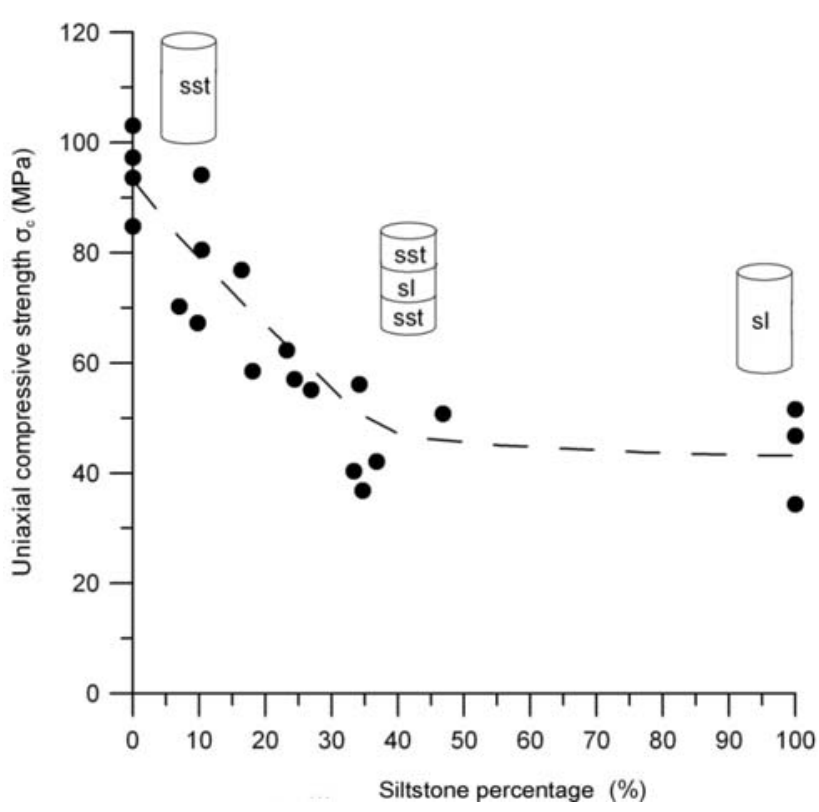

Fig. 13: Uniaxial compressive strength reduction of composite rocks with increasing siltstone volumetric percentage (sst: sandstone, sl: siltstone).

Recent laboratory research for the estimation of the strength and deformability characteristics of heterogeneous rocks is carried out in the laboratory of Engineering Geology and Rock Mechanics, of the Geotechnical Engineering Department, NTUA(Tziallas, 2010). The composite rock specimens tested were made up of disks of sandstone and siltstone which belong to the Ionian flysch formation of Evinochori region (Figure 12). The intermediate siltstone disks were of varying thickness and the volumetric percentage of siltstone for the cylindrical composite specimens ranged from 10 to 50 percent. The uniaxial compressive strength of sandstone specimens ranges from 85 to $105 \mathrm{MPa}$ and of siltstone specimens from 30 to $50 \mathrm{MPa}$.

According to the preliminary test results, the uniaxial compressive strength of composite specimens is significantly reduced when the siltstone percentage is increased from 10\% to 20\% (Figure 13). When the siltstone percentage of composite specimens is increased to about $30 \%$, their uniaxial compressive strength is further reduced and becomes almost equal to the siltstone strength.

Further research is necessary to check the validity of these results and to study the deformability characteristics of composite rocks. 


\section{References}

Button E. A., Schubert W., Riedmueller G., Klima K. \& Medley E.W., 2003. Tunnelling in tectonic melanges - accommodating the impacts of geomechanical complexities and anisotropic rock mass fabrics. International Bulletin of Engineering Geology and the Environment, 63 (2), 109 - 117.

Carter T.G., Diederichs M.S., Carvalho J.L., 2007. A unified procedure for Hoek-Brown prediction of strength and post yield behaviour foe rockmasses at the extreme ends of the rock competency scale. $11^{\text {th }}$ Congress of ISRM, Taylor \& francis Group, London, 161-164.

Christoulas S., Kalteziotis N., Gassios E., Sabatakakis N., Tsiambaos G., 1988. Instability phenomena in weathered flysch in Greece. Proc. 5th Intern. Symposium on Landslides, Lausanne, Vol. 1, 103-108.

Goodman R.E., 1993. Engineering Geology - Rock in Engineering Construction. Smith, M.R. and Collis, L.,eds., John Wiley \& Sons, Inc., 412 p.

Greco O.D., Ferrero A.M., Ogger C., 1993. Experimental and analytical interpretation of the behaviour of laboratory tests on composite specimens. International Journal of Rock Mechanics \& Mining Sciences and Geomechanics Abstracts, 30(7), 1539-1543.

Hoek E., 2007. Rock Engineering. Course notes, 313 p.

Hoek E., Brown E.T., 1997. Practical estimates of rock mass strength. Int. J. Rock Mech. Min. Sci. Geomech. Abstr. 34 (8), 1165-86.

Hoek E., Carranza-Torres C., Corkum B., 2002. Hoek-Brown failure criterion - 2002 edition. In: Proceedings of the fifth NARMS-TAC conference", Toronto, Canada, July 2002, vol I. Balkema, Rotterdam, 267-273.

Hoek E., Marinos P., Marinos V., 2005. Characterization and engineering properties of tectonically undisturbed but lithologically varied sedimentary rock masses. Int. J. Rock Mech. Min. Sci., 42(2), 277-285.

Kahraman S., Alber M, 2006. Estimating the unconfined compressive strength and elastic modulus of a fault breccia mixture of weak rocks and strong matrix. Int. J. Rock Mech. Min. Sci. 43, 1277-87.

Kalteziotis N., Tsiambaos G., 1994. Instability phenomena of weathered flysch with reference in the regions of Ag. Dimitrios and Pili Trikala Dams. Proc. Dam Geology and Greek Experiences, Ed. P. Marinos, 169-177.

Karzulovic L., Diaz A.J., 1994. Comprehensive approach to rock mechanics applied = Integral approach to applied mechanics rocks. Assessment of geomechanical properties Gap in El Teniente mine Braden, $2 \mathrm{v}$.

Lindquist E.S., 1994. The strength and deformation properties of mélange. PhD thesis, Dept. of Civil Engineering, Univ. of California, Berkeley, 264 p.

Lindquist H.S., Goodman R.H., 1994. Strength and deformation properties of a physical model mélange. In: Nelson PP, Laubach SH, editors. Proceedings of the first North American rock mechanics symposium. Rotterdam: Balkema, 843-850.

Marinos P., Hoek E., 2000. GSI: a geologically friendly tool for rock mass strength estimation. In: Proceedings of the GeoEng2000 at the international conference on geotechnical and geological engineering. Melbourne, Technomic publishers. Lancaster, 1422-1446.

Marinos P., Hoek E,. 2001. Estimating the geotechnical properties of heterogeneous rock masses such as fiysch. Bull. Eng. Geol. Env., 60, 82-92.

Marinos V., 2010. New proposed GSI classification charts for weak or complex rock masses. Bulletin of the Geological Society of Greece, Proceedings of the 12th International Congress, Patras (under publication).

Medley E.W., 1994. The engineering characterization of mélanges and similar block-in-matrix rocks (bimrocks). PhD dissertation, University of California, Berkeley, UMJ, Inc., Ann Arbor, MJ, 387 p. 
Medley E.W., 1997. Uncertainty in estimates of block volumetric proportion in melange bimrocks. In Proc. Int. Symp. of Int. Assoc. Eng. Geol., Athens, Greece; June 23-27; A.A. Balkema, Rotterdam, vol. 1, $267-272$.

Medley E.W., 1999. Systematic characterization of mélange bimrocks and other chaotic soil/rock mixtures. Felsbau-Rock Soil Eng., 17, 152-162.

Medley E.W., 2001. Orderly characterization of chaotic Franciscan Mélanges. Felsbau rock Soil Eng., 19, 20-33.

Medley E., Lindquist E.S., 1995. The engineering significance of the scale-indepedence of some Franciscan Melanges in California, USA. In: Daemen, J.K., Schultz, E.A. (eds.):35th US Rock Mech. Sym. Rotterdam. Balkema, 907-914.

Medley E.W., and Sanz. P.R., 2004. Characterization of Bimrocks (Rock/Soil Mixtures) With Application to Slope Stability Problems. In Schubert, W. (ed), Proc. Eurock 2004 and 53rd Geomechanics Colloquium, Salzburg, Austria, Oct 2004.

Moritz B., Grossaeur K., and Schubert W., 2004. Short Term Prediction of System Behaviour of Shallow Tunnels in Heterogeneous Ground Felsbau. J. of Engineering Geology, Geomechanics and Tunnelling. $22(5 / 2004)$, pp. 35-43.

Raymond L.A., 1984. Classification of melanges: in Melanges: Their nature, origin and significance. Special Publication 228, Geol. Soc. of America, Boulder, Colorado; 7-20.

Riedmüller G., Brosch F.J., Klima K. and Medley E.W., 2004. Engineering Geological Classification of Fault Rocks. Poster at Eurock 2004 and 53rd Geomechanics Colloquium, Salzburg, Austria, October 2004.

Sabatakakis N., Koukis G., Tsiambaos G., Papanakli S., 2008. Index properties and strength variation controlled by microstructure for sedimentary rocks. Engineering Geology, 97, 80-90.

Sonmez H., Tuncay E., Gokceoglu C., 2004. Models to predict the uniaxial compressive strength and the modulus of elasticity for Ankara Agglomerate. Int. J. Rock. Min. Sci., Vol. 41, No.5, 717-729.

Sonmez H., Gokceoglu C., Medley E.W., Tuncay E., Nefeslioglu H.A., 2006. Estimating the uniaxial compressive strength of a volcanic bimrock. Int. Rock Mech. Min. Sci., 43, 554-561.

Tziallas G., 2010. Estimation of strength and deformability characteristics of composite rocks. MSc Thesis, Geotecnical Engineering Department, NTUA (in Greek).

Tsiambaos G., Sabatakakis N., 2004. Considerations on strength sedimentary rocks. Engineering Geology, 72, 261-273.

Zainab M., Kamaruzaman M., Cho G. C., 2007. Uniaxial compressive strength of composite rock material with respect to shale thickness ratio and moisture content. The Electronic Journal of Geotechnical engineering, 13, 1-10. 